\title{
Construção de Nação em Angola nas páginas literárias*
}

Resenha: CARVALHO FILHO, Sílvio de Almeida. Angola: História, Nação e Literatura (1975-1985). Curitiba: Editora Prismas, 2016.

Carolina Bezerra de Souza Universidade Federal Fluminense (UFF) lowbezerra@gmail.com

A presente obra que chega ao leitor no ano de 2016 é resultado da tese de doutorado do historiador Silvio de Almeida Carvalho Filho, defendida em 1994 na Universidade de São Paulo (USP). Escrita durante um período em que a produção historiográfica sobre os países africanos ainda era escassa no Brasil, a pesquisa contou também com outros desafios. A instabilidade política de Angola, os longos anos de guerra civil, e a falta de instituições que não sejam, ainda hoje, atreladas diretamente aos interesses do governo, certamente contribuíram para a escolha da literatura como principal fonte do trabalho. Sílvio Carvalho enxergava na escrita literária daqueles escritores as inúmeras complexidades existentes para a formação da identidade angolana e do imaginário social da nação, construído em diálogo com as obras analisadas.

\footnotetext{
*Esta pesquisa recebeu financiamento da Coordenação de Aperfeiçoamento de Pessoal de Nível Superior (CAPES).
} 
Os porquês que nortearam a escolha pela produção literária estão definidos logo no primeiro capítulo, em que o historiador estabelece as intrincadas relações entre a História e a Literatura. A pesquisa desenvolvida na obra traz como proposta valorizar a literatura enquanto fonte - à medida que compreende a escrita literária como uma forma de também escrever o real -, relacionar a produção literária do país com a formação da nação angolana e reconhecer a importância dos literatos na história política do país. O que fica claro a partir dessa pesquisa é como a História do país está atrelada aos movimentos literários existentes que se formaram e como esses trazem desafios aos historiadores por contribuírem com questionamentos e reinterpretações acerca da formação da nação. Estes objetivos são um desafio ainda atuais, visto que ainda há uma grande resistência por parte da historiografia em adentrar no terreno da literatura, devido ao seu descompromisso com o real.

Atualmente, professor aposentado de História da África do Instituto de História da Universidade Federal do Rio de Janeiro (UFRJ), e com uma longa experiência como docente, Sílvio Carvalho se firmou na pesquisa sobre a literatura angolana, que embora ainda incipiente, aos poucos começa a ganhar espaço nos mercados editoriais brasileiros. No presente trabalho, são 56 livros analisados de 129 publicados entre 1975 e 1985, período cronológico em que se estende a pesquisa, além dessas produções, foram analisados a forma como alguns periódicos retratavam e divulgavam a literatura. Os motivos que levaram a essa seleção não ficaram evidentes na pesquisa, em que o historiador se utilizou de uma amostra aleatória para a escolha das obras e escritores, de modo que não ficasse restrito apenas a fatores estéticos ou ideológicos. ${ }^{1}$ Já os anos escolhidos foram em função da independência do país em 1975 e do 2을 Congresso do Movimento Popular de Libertação de Angola (MPLA) feito em 1985, em que realizou um balanço dos dez anos de independência. Compreende-se que nesse período as obras literárias dialogaram com o projeto de formação da nação, inclusive iniciando as primeiras críticas ao governo.

É importante ressaltar que dentre os escritores analisados, podemos traçar um perfil do escritor angolano, o que também aponta para as problematizações que cercaram a formação da identidade angolana: o universo, sobretudo, urbano, de onde derivou a maior parte dos literatos, a questão racial, visto que muitos escritores eram brancos ou mestiços e a influência socialista, que os aproximou do projeto nacional do MPLA. Todas essas características, trabalhadas de

1 CARVALHO FILHO, Sílvio de Almeida. Angola: História, nação e Literatura (1975-1985). Curitiba: Editora Prismas, 2016. p.28

Odeere: revista do programa de pós-graduação em Relações Étnicas e Contemporaneidade - UESB. ISSN 2525 4715, Ano 1, número 2, volume 1, Julho - Dezembro de 2016. 
maneira pormenorizada em alguns capítulos, contribuem para refletirmos sobre as contradições presentes na construção da angolanidade a partir da vida individual dos escritores, principalmente, ao levarmos em consideração a importância desses intelectuais para a escrita da história do país. Podemos afirmar que a prática política desses escritores se relacionava diretamente com o que escreviam.

Dessa forma, Sílvio Carvalho optou pela escolha temática para dividir os capítulos do seu livro. A representação do mundo colonial é um tema que se destaca na obra, visto que diversos escritores se debruçaram sobre estas questões em seus romances. A exploração colonial era denunciada, assim como o colonizador retratado como "um sujeito prepotente". ${ }^{2} \mathrm{~A}$ opressão imposta no mundo do trabalho, nas relações raciais - que demarcavam espaços de convivência - e na imposição cultural registravam nas narrativas literárias a opressão do colonizado. Ao ressaltar essa realidade, buscava-se partir das complexidades existentes no período colonial para valorizar a emergência do nacionalismo plural e multirracial defendido pelo MPLA. Nesse sentido, a angolanidade era retratada pelos literatos como um fator mais cultural que racial. ${ }^{3}$

Ao compreender que a literatura deveria fazer parte de um projeto político revolucionário, os escritores retratados defendiam que as contradições existentes entre o povo angolano deveriam ser superadas, dando espaço para a construção de uma nação socialista. Os problemas raciais e étnicos eram postos como um meio do colonizador dividir o povo angolano para poder governar, dessa forma, construíam-se personagens que chamavam a atenção para a discriminação racial existente tanto para o "branco de segunda", aquele nascido em Angola, quanto para o negro - o que os colocava em um mesmo patamar de desigualdade. Buscava-se a partir dessas construções evidenciar o inimigo real do povo angolano, o colonizador.

Diversos temas se entrecruzam no livro à medida que os desafios para a construção do nacionalismo são postos. A questão racial sempre foi uma constante, que perdurou mesmo após a independência. As disputas políticas em Angola pelos principais movimentos nacionalistas trouxe à tona os problemas raciais encontrados na sociedade, que se mantinha dividida com o fim do colonialismo. O MPLA era acusado de ser uma representação dos interesses dos brancos e mestiços, devido a enorme presença desses grupos nos quadros do movimento; por outro lado, a UNITA seria a representante dos pobres e negros. Essas afirmativas eram duramente combatidas

\footnotetext{
2 CARVALHO FILHO, Op. Cit. p.99

3 CARVALHO FILHO. Op. Cit. p.159
} 
pelo governo e pela literatura, atrelada a um projeto nacional socialista, que buscava uma concepção de integração social, independente de questões raciais. Para isso, como ressalta Sílvio Carvalho, "a bravura dos guerrilheiros" durante as guerras de libertação em Angola eram exaltadas nas páginas literárias.

Os fatores de integração e solidariedade nacional eram reafirmados e reconstruídos a partir do desenvolvimento de uma memória nacionalista do início do século XX, que teve o seu auge no espírito guerrilheiro ao longo dos últimos anos que antecederam a independência. Já para a consolidação desse projeto nacional, a língua portuguesa representou a busca pela unidade diante da pluralidade étnica existente, assim como a valorização dos costumes do povo e das suas raízes propunha despertar o que havia em comum ao povo daquela terra. Para esse movimento, o MPLA era visto e apresentado nas obras como o dirigente e a grande vanguarda para a construção da nação. O processo de construção da identidade angolana perpassava esses caminhos e a literatura escrevia essa história, em que "literatura e patriotismo achavam-se imbricados". 4

Por outro lado, por mais que a expressão da nacionalidade angolana entre os literatos estivesse em diálogo com o projeto do MPLA, o autor aponta que algumas obras não deixaram de colocar suas críticas ao governo e aos desvios ao projeto nacionalista. Muitas vezes a desilusão ao projeto nacionalista pretendido tomou conta das páginas literárias. Nesse momento, ficam evidentes as diferenças entre a literatura publicada na imprensa, amplamente dominada por escritores da cúpula governamental, e os outros escritores, entre eles: Pepetela, Boaventura e João Melo, que denunciavam em suas narrativas a traição dos ideais socialistas. Todavia, esses escritores representavam uma minoria dentre o movimento literário, que na maioria das vezes silenciou, como chama atenção Sílvio Carvalho, a corrupção e o domínio político de uma pequena elite burguesa.

Os dois últimos capítulos da obra se voltam para esses questionamentos. Intitulados "A Utopia da Nação socialista" e "Não foi isso que combinamos", eles propõem ressaltar como alguns escritores se sentiram duramente decepcionados com os rumos do novo regime político. Após dez anos de independência não era mais possível culpabilizar o período colonial por todos os problemas que a sociedade angolana ainda enfrentava. Era preciso olhar para dentro do regime e tentar enxergar as escolhas que resultaram na permanência de uma sociedade desigual, com um alto índice de problemas sociais que esperava-se serem resolvidos.

$4 \quad$ CARVALHO FILHO, Op. Cit. p.224

Odeere: revista do programa de pós-graduação em Relações Étnicas e Contemporaneidade - UESB. ISSN 25254715, Ano 1, número 2, volume 1, Julho - Dezembro de 2016. 
Conforme aponta o autor, os textos traziam questionamentos sobre os rumos que o governo tomava. A fata de um regime democrático, o aumento do autoritarismo do Estado, a propagação da corrupção no governo e os desvios do projeto socialista passaram a ser problematizados em alguns livros, por vezes, a partir de uma escrita comparativa com os países independentes do continente africano. É interessante notar que ao longo dos anos essas problematizações vão continuar aparecendo nas literaturas africanas, tornando a crítica ainda mais ácida em relação ao Estado. Quando Sílvio Carvalho escreve a sua pesquisa de doutoramento, muitos escritores angolanos ainda estão comprometidos com o governo do MPLA, inclusive fazendo parte diretamente dos cargos governamentais. Podemos perceber que a crítica nos livros publicados durante esse período ainda buscavam uma mudança de dentro. Posteriormente, o rompimento de muitos desses escritores com o regime irá aprofundar a crítica.

Embora os novos debates historiográficos não estejam presentes no livro, devido a distância da sua pesquisa e atual publicação, o trabalho está longe de ser uma obra datada. As problematizações levantadas em larga escala, ao longo dos capítulos, merecem a atenção de pesquisadores, principalmente, ao ganharem um novo enfoque a partir do crescimento dos estudos africanos. E, infelizmente, ainda nos deparamos com a relutância de alguns historiadores em retratar a literatura como fonte principal de um trabalho historiográfico. Dos anos que separam a pesquisa dos dias de hoje, inúmeros trabalhos sobre Angola foram desenvolvidos, e o que notamos é a presença marcante da literatura na história do país. É impossível dissociar a construção da nação angolana sem nos referirmos aos seus movimentos literários. Para dar conta dessa relação, Sílvio Carvalho buscou dialogar através das inúmeras obras literárias do período, o que Ihe exigiu uma pesquisa de fôlego para chegar a uma análise geral.

Por outro lado, compreendemos que a riqueza da pesquisa aqui retratada abre novas portas. Cada capítulo desenvolvido merece ser analisado em uma escala microscópica, pois abre um leque de informações para os estudos angolanos. O pioneirismo em retratar a literatura enquanto fonte deixou algumas lacunas que merecem uma continuidade nas pesquisas. Conhecer os escritores das obras a partir das suas individualidades, assim como o momento de escrita dos livros, as diferenças editoriais que influenciam na recepção dos leitores, os lugares de publicação no livro apontam para as literaturas nos periódicos atrelados ao governo e as que apresentam um caráter independente, mas nem sempre há essa distinção clara no texto. Todas essas provocações podem abrir novas possibilidades de interpretação. Além disso, a presença marcante da União dos 
Escritores Angolanos, uma instituição ligada ao MPLA, na publicação de inúmeros livros trabalhados ao longo da pesquisa, também exige uma maior problematização, pois ainda parecem desconhecidos os meios que levam às escolhas dos periódicos para a publicação.

De toda forma, fica evidenciada na obra aqui apresentada o destaque que a literatura obteve na construção do imaginário social da nação angolana, contribuindo para a formação de uma identidade nacional que se fazia em oposição ao colonizador. Como afirma a historiadora Sandra Pesavento, a literatura importa como fonte historiográfica não pela sua testemunha de verdade ou autenticidade do fato narrado, mas pelo seu valor de problema, "pois através da ficção ela revela e insinua as verdades da representação e do simbólico" ${ }^{5}$, que abrem novas possibilidades a partir das verossimilhanças possíveis que muitas vezes não aparecem nos documentos oficiais. Por estas questões, a leitura do livro interessa a quem se debruça sobre essa relação complexa entre a história e literatura e a todos os interessados pela história de Angola na contemporaneidade. As reflexões postas nas páginas escritas pelo professor Sílvio Carvalho são intrigantes e estão longe de estarem saturadas.

\section{Referência bibliográfica}

CARVALHO FILHO, Sílvio de Almeida. Angola: História, nação e Literatura (1975-1985). Curitiba: Editora Prismas, 2016. p.28

PESAVENTO, Sandra. História e Literatura, uma Velha Nova-História. In.: COSTA, Cléria B. e MACHADO, Maria Clara T. (Org.) História e Literatura. Identidades e Fronteiras. Uberlândia: EDUFU, 2006.

\footnotetext{
5 PESAVENTO, Sandra. História e Literatura, uma Velha Nova-História. In.: COSTA, Cléria B. e MACHADO, Maria Clara T. (Org.) História e Literatura. Identidades e Fronteiras. Uberlândia: EDUFU, 2006.
} 
Carolina Bezerra de Souza: Doutoranda em História da Universidade Federal Fluminense, em que desenvolve a pesquisa sobre as relações de poder em Angola a partir de romances do escritor angolano Pepetela. Atualmente é tutora do Ensino de graduação à distância em História da Unirio, faz parte do corpo editorial da revista Cantareira e é membro do grupo interestitucional Áfricas.

Artigo recebido para publicação em: Outubro de 2016.

Artigo aprovado para publicação em: Dezembro de 2016. 